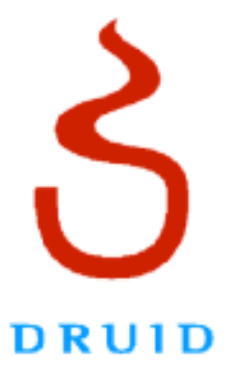

DRUID Working Paper No. 06-29

Cumulative Innovation, Sampling and the Hold-Up Problem

By

Rufus Pollock 


\title{
3
}

D R U 1 D

\section{Cumulative Innovation, Sampling and the Hold-Up Problem}

\author{
Rufus Pollock \\ Cambridge University \\ Queens' College \\ Cambridge CB3 9ET \\ United Kingdom \\ E-mail: rufus@rufuspollock.org
}

2006-10-04

\begin{abstract}
:
With cumulative innovation and imperfect information about the value of innovations, intellectual property rights can result in hold-up and therefore it may be better not to have them. Extending the basic cumulative innovation model to include 'sampling' by second-stage firms, we find that the lower the cost of sampling, or the larger the differential between high and low value second-stage innovations, the more likely it is that a regime without intellectual property rights will be preferable. Thus, technological change which reduces the cost of encountering and trialling new 'ideas' implies a reduction in the socially optimal level of rights such as patents and copyright.
\end{abstract}

Key words: Cumulative Innovation, Hold-Up, Sampling, Intellectual Property

Jel codes: K3, L5, O3

ISBN 87-7873-221-2

\section{Acknowledgement}

I thank my supervisor, Rupert Gatti, and my advisor, David Newbery, for guidance and many helpful discussions. This paper was first presented at the 2006 DRUID Summer Conference and I wish to thank the participants there for a variety of useful comments. Any remaining errors are, of course, mine. 


\section{Introduction}

[The] 90-minute documentary [Wanderlust] ... was also a window into the frustrations of making a clip-intensive film dependent on copyright clearance, which has become hugely expensive in the past decade. Initial quotations for the necessary sequences came to more than $\$ 450,000$, which would have raised by half the cost of the IFC film.... "Paramount wanted \$20,000 for 119 seconds of 'Paper Moon,' " Ms. Sams said. "The studios are so afraid of exploitation that they set boundaries no one will cross. Even after the prices were cut, we were $\$ 150,000$ in the hole."

The New York Times, May 28, 2006 No Free Samples for Documentaries: Seeking Film Clips With the Fair-Use Doctrine.

Cumulative innovation and creativity, whereby new work build upon old, is a pervasive phenomenon. However it was not until recently that it received significant attention in the literature. The seminal paper in this regard is that of Green and Scotchmer (1995). They introduced a two-stage innovation model in which the second innovation is enabled by, or builds upon, the first. Their paper primarily concerns itself with how rents are divided between innovators at the two stages, in particular with the extent to which the first innovator is (under-)compensated for her contribution (the option value) to the second innovation. They investigate how different policy levers related to intellectual property rights, in particular breadth ${ }^{1}$, could be used to affect the bargaining (or its absence) between different innovators and hence the resulting payoffs.

A central feature of their model, as well as subsequent work that extended it, was an assumption that knowledge of costs and returns, whether deterministic or stochastic, was shared equally by innovators at different stages (i.e. was common knowledge). With common knowledge all mutually beneficial transactions are concluded, using ex ante licenses where necessary to avoid the possibility of hold-up of second-stage innovators.

However this assumption is problematic. If all innovators share the same information why do we need different innovators at first and second stages and why concern ourselves with licenses and bargaining if a single innovator could just as easily do it all? The obvious answer is that this assumption is wrong, something suggested by a cursory observation of 
reality: many different firms engage in innovation precisely because they have specialized skills and knowledge that make it effective for them rather than another firm to engage in a given area. This contention is backed up by empirical data and substantial anecdotal ${ }^{2}$ evidence. For example, Anand and Khanna (2000) demonstrate that most licensing agreements are concluded ex post and not ex ante (for example, in the computer and electronic industries, which are well known for the cumulativeness of their innovation, ex ante agreements account for only 5 or $6 \%$ of all agreements).

Thus, in this paper we investigate cumulative innovation under asymmetric information, that is, for example, where the first-stage innovator only has a probabilistic prior over the second-stage innovator's cost/values but the second-stage innovator knows them precisely ${ }^{3}$. This allows us to investigate hold-up: a situation whereby second-stage innovations are held-up (prevented or delayed) by the first-stage innovator. In such circumstances the policy choice, in its crudest form, is between having intellectual property rights (patents or copyright) available to first-stage innovators (which second-stage innovators infringe and therefore must license) and not having intellectual property rights (second-stage innovators do not infringe and therefore may do what they wish).

This approach adds another dimension to the question of how profit is divided between innovators at different stages. Seen in this light, it also has direct analogies with existing results related to the question of whether second-stage innovations should be infringing $(\mathrm{I})$ or non-infringing $(\mathrm{NI})$. For example, Green and Scotchmer consider explicitly the situation where the value of the second innovation is only known in terms of a probability distribution and show that in such circumstances 'breadth' should be finite. This corresponds to at least some second-stage innovations being non-infringing. Denicolo (2000) extends Green and Scotchmer's model with patent races at each stage and finds that in some circumstances it will be better to make second-stage innovations non-infringing (in this model one trades off faster second-stage innovation with non-infringement against faster first-stage innovation when there is infringement).

A model much closer to the basic one presented here is provided by Bessen (2004). His paper also considers hold-up of second-stage products or innovations by first-stage innovators. However in his model the focus is primarily on whether ex ante or ex post licensing occurs. He assumes that ex post royalty shares are determined exogenously - perhaps as a policy variable or determined by invent-around costs and other factors - and shows that the socially optimal ex post royalty share is less than that obtained in ex ante bargaining. Here we take a more explicit approach that allows us to determine optimal policy as a direct function of fundamental parameters such as the probability of an innovation being of a high or low value type. 
The second model presented extends the first by introducing the idea of sampling, whereby second-stage firms can sample first-stage innovations before deciding which to use (and therefore license). Sampling benefits a firm by increasing the probability of having a high value innovation but is costly. We find that, in general, the lower the sampling costs or the larger the differential between high and low value second-stage innovationsi, the more likely it is that a regime without intellectual property rights will be preferable. Thus, in the context of this model, technological change which reduces the cost of encountering and trialling new 'ideas' should imply a reduction in the socially optimal level of intellectual property rights such as patents and copyright. 


\section{A Two-Stage Model of Cumulative Innovation}

\section{The Model}

We adopt a simple model of two stage innovation in which the second innovation builds upon the first in some manner - either as an application or as an extension of it. The model, which is specified in detail below, can be summarized in the following diagram:

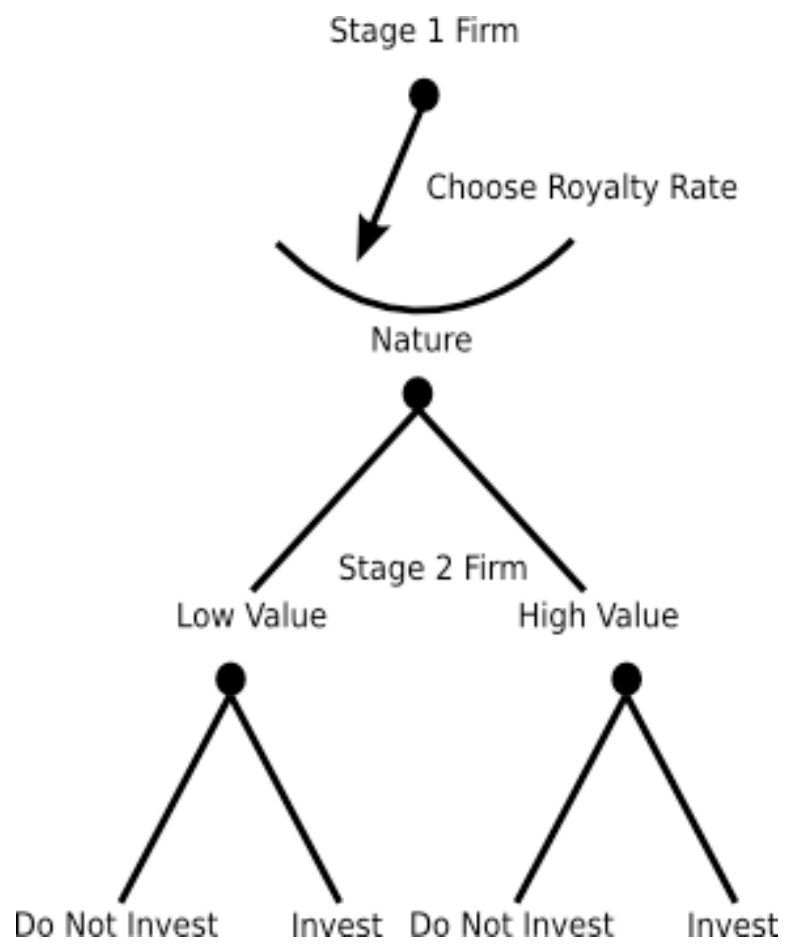

Figure 1: Game Tree Post First-Stage Innovator Investment. Note that, for simplicity, the initial nodes at which Nature determines value type of first-stage firms and first-stage firms make their investment decisions have been omitted. 


\begin{tabular}{|c|c|c|c|c|c|c|}
\hline Player & \multicolumn{6}{|c|}{ Second-Stage Innovator } \\
\hline \multirow{4}{*}{$\begin{array}{l}\text { First-Stage } \\
\text { Innovator }\end{array}$} & \multirow{2}{*}{$\begin{array}{l}\text { Value } \\
\text { Type }\end{array}$} & & \multicolumn{2}{|c|}{ Low (p) } & \multicolumn{2}{|c|}{ High (1-p) } \\
\hline & & Action & NI & I & NI & $\mathbf{I}$ \\
\hline & Low (q) & \multirow{2}{*}{$\mathbf{r}$} & $\begin{array}{l}v_{L}^{0}, \\
0\end{array}$ & $\begin{array}{l}v_{L}^{0}+r, \\
v_{L}-r\end{array}$ & $\begin{array}{l}v_{L}^{0}, \\
0\end{array}$ & $\begin{array}{l}v_{L}^{0}+r \\
v_{H}-r\end{array}$ \\
\hline & $\begin{array}{l}\text { High } \\
(1-q)\end{array}$ & & $\begin{array}{l}v_{H}^{0}, \\
0\end{array}$ & $\begin{array}{l}v_{H}^{0}+r, \\
v_{L}-r\end{array}$ & $\begin{array}{l}v_{H}^{0}, \\
0\end{array}$ & $\begin{array}{l}v_{H}^{0}+r, \\
v_{H}-r\end{array}$ \\
\hline
\end{tabular}

Action and Payoff Matrix Assuming First-Stage Innovator Invests (I/NI = Invest/Do Not Invest, $r$ = Royalty Rate)

Innovations are described by their net value $v$ (revenue minus costs). Because our interest lies in examining the trade-off between innovation at different stages we make no distinction between social and private value (i.e. there are no deadweight losses) and $v$ may be taken to be either.

We assume the base (first) innovation takes two values: low $\left(v_{L}^{0}\right)$ and high ( $\left.v_{H}^{0}\right)$ with probability $q,(1-q)$ respectively. We assume that $v_{L}^{0}<0$ so that without some additional source of revenue, for example from licensing (see below), the innovation will not be produced. Applications Second stage innovations also take two values: low $\left(v_{L}\right)$ and high $\left(v_{H}\right)$ with probability $p,(1-p)$ respectively. While the value of a second-stage innovation is known to the innovator who produces it, the value is not known to the owner of the first-stage innovation which it builds upon (this could occur because of imperfect information regarding revenue, costs or both). Without loss of generality we shall assume that the number (or measure) of second-stage innovations per first-stage innovation is one (having $\mathrm{N}$ second-stage innovations per first-stage innovation would just require replacing $v_{H}$ with $N v_{H}$ and $v_{L}$ with $N v_{L}$ ).

\section{Intellectual Property Rights and Licensing}

We wish to consider two regimes: one with intellectual property rights (IP) and one without (NIP). With intellectual property rights every second-stage innovator will require a license from the relevant first-stage innovator in order to market her product, while without intellectual property rights she may market freely without payment or licence ${ }^{4}$.

We assume that the direct returns to the first innovator $\left(v_{0}\right)$ are unaffected by the intellectual property rights regime. While this may appear to be a 
strong assumption, our focus in this paper is on the division of rents between first and second-stage innovators and we therefore believe that little is lost by this simplification (there is further discussion of this in the paper's conclusion).

We take the licence to define a lump-sum royalty payment $r$ and we assume that when royalty income is forthcoming it is sufficient to ensure that all first-stage innovations are produced (i.e. $r>-v_{L}^{0}$ ).

\section{Sequence of Actions}

The sequence of actions in the model is:

1. Nature determines value type of first-stage innovator

2. A first-stage innovator decide whether to invest. If the first-stage innovator does not invest the game ends and all payoffs are zero. Assuming the first-stage innovator invests the game continues.

3. The first-stage innovator sets the royalty rate (if there are no intellectual property rights then the royalty rate is 0 )

4. Nature determines value type of a second-stage innovator

5. Given this royalty rate second stage firms decide whether to invest

6. Payoffs are realized

\section{Solving the Model}

Define a constant, $\alpha$, as follows:

$\alpha \equiv \frac{v_{H}-v_{L}}{v_{H}}$

Proposition 1: With intellectual property rights the game defined above has the following unique pure-strategy Nash equilibrium. A second-stage innovator invests if and only if its realized value is greater than or equal to the royalty rate (i.e. net profits are non-negative). A first-stage innovator invests and sets a low royalty rate $(\mathrm{RL}), r_{L}=v_{L}$ if the probability of a low value innovation $(p)$ is greater than $\alpha$ and a high royalty rate $(\mathrm{RH}) r_{H}=v_{H}$ otherwise.

Proof: a second-stage innovator of type $\mathrm{X}$ faces a payoff of $v_{X}-r$ if she invests and 0 if she does not. Thus, a second-stage innovator, seeking to maximize profits will invest if and only if $v_{X} \geq r$.

Given this the first-stage innovator faces a straightforward selection/pooling problem with a choice between a low royalty rate $r_{L}=v_{L}$ (all second-stage innovations produced) or a high royalty rate $r_{H}=v_{H}$ (only high value second-stage innovations produced) with all other possible royalty rates 
yielding a lower payoff. In the first case the payoff is $r_{L}$ while in the second it is $(1-p) r_{H}$. Thus a low royalty rate should be chosen if and only if (assuming that if payoffs are equal a low royalty is chosen):

$r_{L} \geq(1-p) r_{H} \Leftrightarrow p \geq \frac{r_{H}-r_{L}}{r_{H}}=\alpha$

Finally a first-stage innovator will always choose to invest because in the presence of royalty income net profits are (assumed above) to be non-negative. QED.

Proposition 2: without intellectual property rights the game above has the following solution: both types of second-stage innovators invest but of first-stage innovators only those that have 'high-value' innovations invest (there are $1-q$ of these type).

Proof: trivial.

\section{Welfare}

To determine welfare we need to know the 'trade-off' between first and second-stage innovations that occurs when revenue is allocated from one to the other by licensing. As stated above, without revenue from second-stage innovations a proportion $q$ of first-stage innovations are not produced. We have assumed that when royalty income is forthcoming it is sufficient to ensure that all first-stage innovations are produced (i.e. $r>v_{L}^{0}$ ). Thus in the absence of royalty income there are $q$ first-stage innovations that are not produced, and these have average value $v_{L}^{0}$. The remaining innovations $(1-q)$ are produced irrespective of whether royalty revenue is received and have average value $v_{H}^{0}$.

Let us now consider social welfare in the four possible situations given by (IP, RL), (IP, RH), (NIP, RL), (IP, RH) as well as the difference in welfare between an intellectual property regime and a no intellectual property regime (IP-NIP). Due to our earlier assumption welfare is determined by calculating total net value. Define for convenience $v_{0}=q v_{L}^{0}+(1-q) v_{H}^{0}$, the average first-stage innovator costs (if all innovate), and $v=p v_{L}+(1-p) v_{H}$, the average second-stage innovator costs (if all innovate). We can then summarize the welfare situation in the following table: 


\begin{tabular}{|c|c|c|}
\hline & $\mathbf{R L}$ & $\mathbf{R H}$ \\
\hline $\mathbf{I P}$ & $v_{0}+v$ & $v_{0}+(1-p)\left(v_{H}\right)$ \\
\hline $\mathbf{N I P}$ & $(1-q)\left(v_{H}^{0}+v\right)$ & $(1-q)\left(v_{H}^{0}+v\right)$ \\
\hline $\mathbf{I P}-\mathbf{N I P}$ & $q\left(v_{L}^{0}+r_{L}\right)+q\left(v-r_{L}\right) \geq 0$ & $q\left(v_{L}^{0}+(1-p) v_{H}\right)-(1-q) p v_{L}$ \\
\hline
\end{tabular}

\section{Policy Implications}

Proposition 3: when a low royalty will be set $(p \geq \alpha)$ i.e. low value innovations are sufficiently frequent and/or the difference between low and high value innovations is sufficiently small) a patenting regime is optimal.

Proof: in the low royalty $(R L)$ situation all second-stage innovations will be produced whether there is IP or not. In that case one wishes to maximize returns to the first innovator and patents do this by transferring rents via licensing. Formally in the low royalty case the welfare difference between patents and no patents (IP-NIP) is:

$q\left(v_{L}^{0}+r_{L}\right)+q\left(v-r_{L}\right)$

Both of the terms in brackets are positive implying that the intellectual property regime delivers higher welfare than the no intellectual property (NIP) regime. QED.

The situation when the high royalty will be set is less clear. First define $\beta$ as the proportion of the total royalty payment $\left((1-p) r_{H}\right)$ that would be 'used up' if all first-stage innovator were low value:

$\beta \equiv \frac{-v_{L}^{0}}{(1-p) r_{H}}$

Note that $v_{L}^{0}$ is negative and must be less in absolute terms than the royalty received $(1-p) r_{H}$ as we are assuming that the royalty enables low value first-stage innovators to produce. Under this definition $\beta=1$ corresponds to all the royalty being used up to fund first-stage innovators higher costs while $\beta \approx 0$ means all of the royalty payment is being retained as extra profits (and welfare).

Proposition 4: when a high royalty will be set $(p<\alpha)$ an intellectual property regime will be preferable to a no intellectual property (NIP) regime if and only if (NB: in fact with equality one would be indifferent): 
$q \geq \frac{p v_{L}}{(1-\beta)(1-p) v_{H}+p v_{L}}=\frac{\text { Hold-up Loss }}{\text { Net Surplus Under Licensing + Hold-up Loss }}$

Proof: From the table above an IP regime yields higher welfare than an NIP regime if and only if:

$q\left(v_{L}^{0}+(1-p) v_{H}\right) \geq(1-q) p v_{L}$

Making $q$ the subject of this inequality and using $\beta$ we obtain the stated result. QED.

We can represent this result graphically as follows:

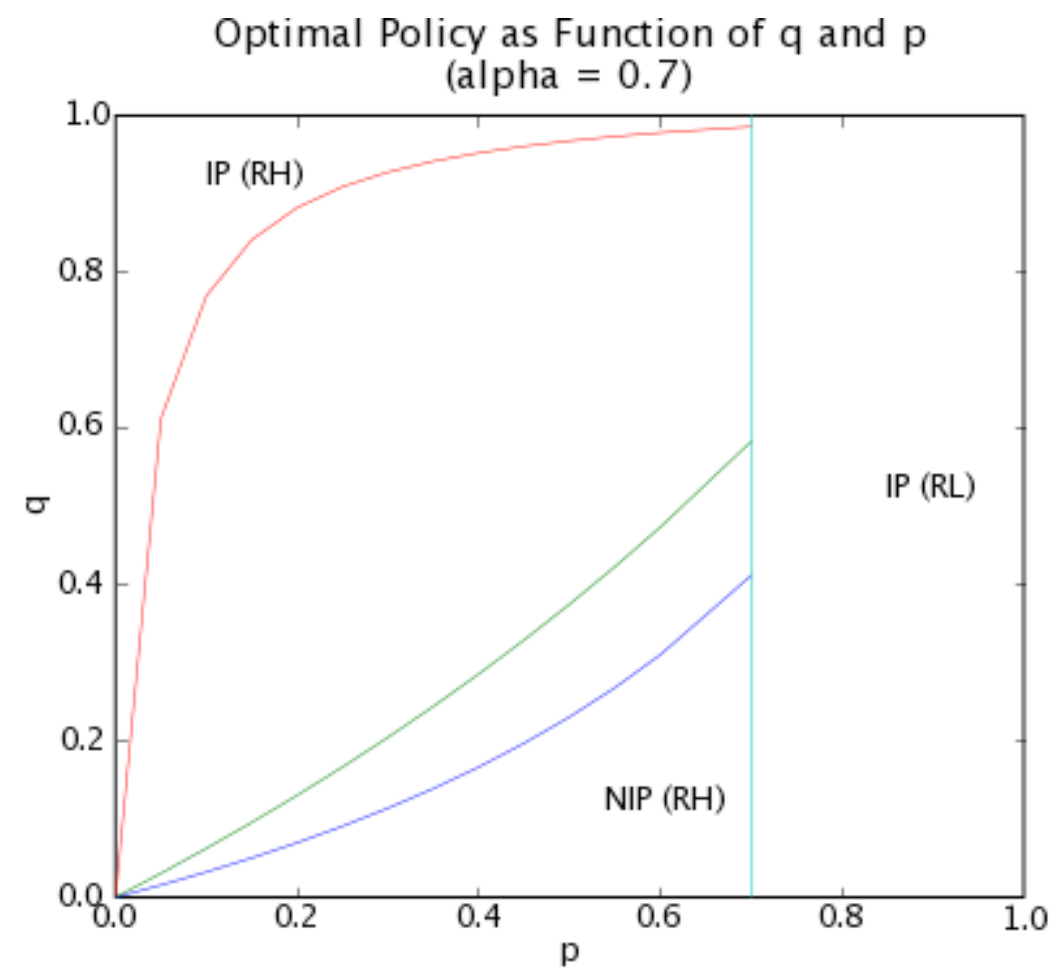

Figure 2: A diagram showing optimal policy regions as a function of the exogenous probabilities of a low value first-stage innovation $(q)$ or a low value second-stage innovation $(p)$. $\alpha$ equals 0.7 so the right of the line $p=0.7$ there is a low royalty $(\mathrm{RL})$ and an IP regime is optimal. To the left of that line we have shown three different 'horizontal' lines which show the cutoff between IP being optimal (above the line) and NIP being optimal (below the line). The horizontal lines correspond (in ascending order) to $\beta$ equal to $0,0.5$, and 0.99 .

Remarks: in the high royalty case $(\mathrm{RH}) p$ is the proportion of second-stage innovations that do not occur with intellectual property rights (due to high 
royalties and the resulting hold-up) while $q$ is the proportion of first-stage innovations that do not occur without intellectual property rights. As first-stage innovations enable second stage ones when we lose a first-stage innovation we lose all dependent second stage ones as well. Due to this, when $\beta$ is low for no intellectual property rights to be preferable $p$ must be substantially higher than $q$. It is only then that the cost of intellectual property rights, in terms of lost second-stage innovations, will outweigh the gains in terms of more first-stage (and dependent second-stage) innovations.

As $\beta$ increases the area in which no intellectual property rights are preferable will increase, with the line separating the two regions moving upwards. In the limit as $\beta$ tends to 1 - which corresponds to most royalty income being used by a low value first-stage innovator to pay costs - the marginal $q$ tends to 1 , that is it is optimal to have intellectual property rights only if all first-stage innovations are of a low value type. 


\section{Cumulative Innovation with Sampling Costs}

\section{Introduction}

This model extends the previous by the introduction of sampling by second stage firms. In this situation second stage firms can only use first-stage innovations that they have encountered by some form of costly sampling (for example purchasing a good that embodies the innovation). The more products they sample, the more likely it is a second stage firm comes up with a good idea of its own - which is modelled, in this case, by the firm's innovation being of high, rather than of low, value.

Obvious real-world examples of such a situation would be software and music. In software a new application will likely combine many ideas (and even code) from previous products. But ideas can only come from applications that one has encountered (note that for re-use of code that means access to the source so the software must be open-source). In music, particularly modern music, re-use either explicit or implicit is ubiquitous. For example, in dance and hip-hop, 'sampling', whereby a small section of a previous work is directly copied and then repeated or reworked in some manner, is the very basis of the genre. More generally all composers whether classical or modern use previous musical, ideas, motifs, and melodies as parts of new works ${ }^{5}$.

\section{The Model}

The model is exactly the same as the basic one except for the addition of an initial period in which sampling by second stage firms takes place. The level of sampling then influences whether the second-stage innovation is of high or low value. Define the following variables:

1. $k$, the number of stage 1 products stage 2 firms choose to sample (via purchase, observation etc)

2. T the cost of each sample

3. As before there are two types of stage 2 firms, high and low value: $v_{H}, v_{L}$

4. $p(k)$, probability of being a low value firm given that $k$ products are sampled. Naturally $p^{\prime} \leq 0$ (otherwise no benefit of observing). We also assume diminishing returns for sampling so that $p " \geq 0$ and that if no sampling takes place all firms are of low value type $(p(0)=1)$. The functional form $p(k)$ is assumed to be common knowledge.

5. $r$, the lump-sum royalty rate set by stage 1 firms

6. $N$, the number of potential stage 2 firms 
The sequence of actions here is the same as in the original model except for the fact that we now have two options as to when the royalty can be set: either after or before sampling (but as in the original model still before the second-stage innovators take their investment decision). We shall refer to these two cases as royalty-after-sampling and royalty-before-sampling. Here we will confine our attention to royalty-after sampling ${ }^{6}$. The sequence of decisions in that case is shown in the following diagram:

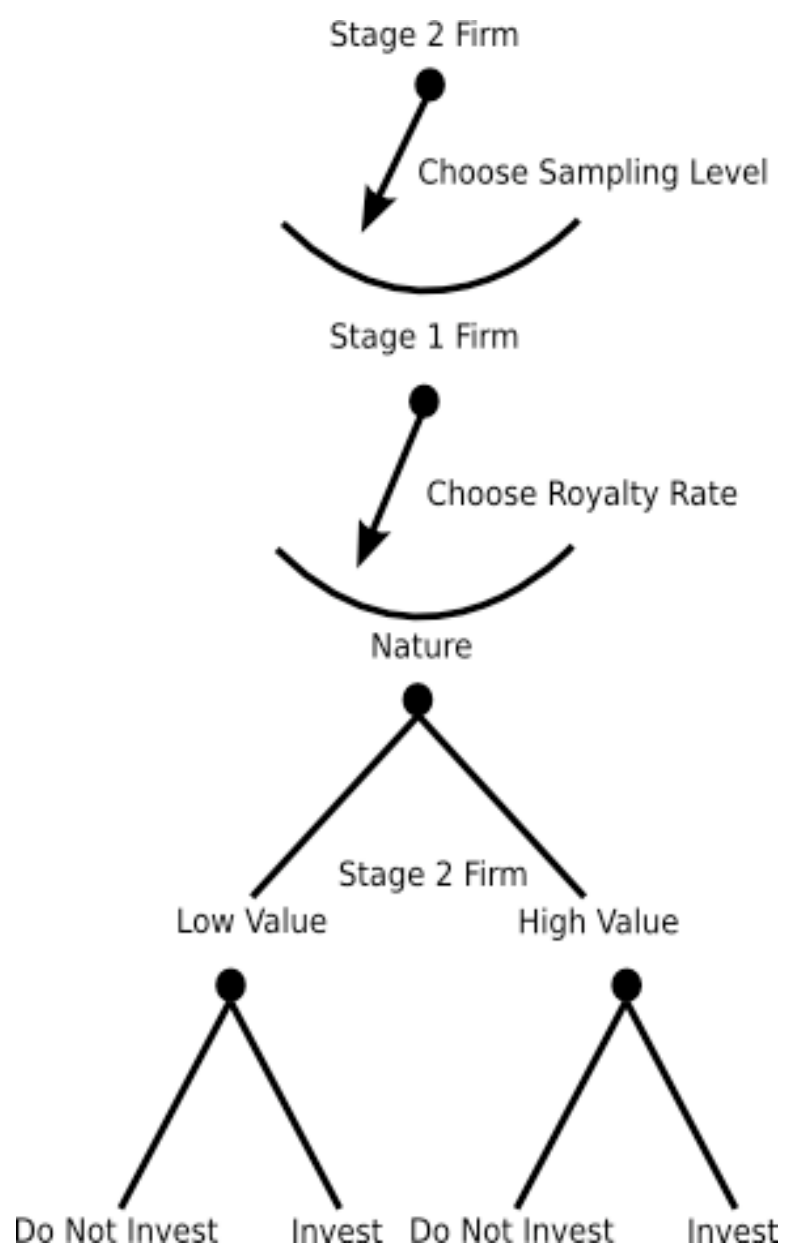

Figure 3: Game Tree Post First Stage Innovator Investment. Note that, for simplicity, the initial nodes at which Nature determines value type of first stage firms and first-stage firms make their investment decisions have been omitted. 


\begin{tabular}{|c|c|c|c|c|c|c|c|}
\hline \multirow[t]{2}{*}{ Player } & \multicolumn{7}{|c|}{ Second-Stage Innovator } \\
\hline & Action & & & \multicolumn{4}{|c|}{ Sample (k) } \\
\hline \multirow{4}{*}{$\begin{array}{l}\text { First-Stage } \\
\text { Innovator }\end{array}$} & & Value & & & $w(p(k))$ & Hig & $h(1-p(k))$ \\
\hline & & & Action & NI & $\mathbf{I}$ & NI & $\mathbf{I}$ \\
\hline & & $\begin{array}{l}\text { Low } \\
\text { (q) }\end{array}$ & \multirow[b]{2}{*}{$\mathbf{r}$} & $\begin{array}{l}v_{L}^{0}, \\
-k \mathrm{~T}\end{array}$ & $\begin{array}{l}v_{L}^{0}+r, \\
v_{L}-r-k \mathrm{~T}\end{array}$ & $\begin{array}{l}v_{L}^{0}, \\
-k T\end{array}$ & $\begin{array}{l}v_{L}^{0}+r, \\
v_{H}-r-k \mathbf{T}\end{array}$ \\
\hline & & $\begin{array}{l}\text { High } \\
(1-q)\end{array}$ & & $\begin{array}{l}v_{H}^{0} \\
-k \mathrm{~T}\end{array}$ & $\begin{array}{l}v_{H}^{0}+r, \\
v_{L}-r-k \boldsymbol{\top}\end{array}$ & $\begin{array}{l}v_{H}^{0} \\
-k \mathbf{T}\end{array}$ & $\begin{array}{l}v_{H}^{0}+r, \\
v_{H}-r-k \top\end{array}$ \\
\hline
\end{tabular}

Action and Payoff Matrix Assuming First-Stage Innovator Invests (I/NI = Invest/Do Not Invest, r = Royalty Rate)

\section{Solving the Model}

Define the constant $k_{\alpha}$ as the sampling level such that $p\left(k_{\alpha}\right)=\alpha$ where $\alpha$ is as defined in the basic model, i.e.

$\alpha \equiv \frac{v_{H}-v_{L}}{v_{H}}$

Next define $k_{2}$ implicitly as follows:

$p^{\prime}\left(k_{2}\right)=\frac{-\mathbf{T}}{v_{H}-v_{L}}$

Proposition 5: With intellectual property rights (IP) The perfect Bayesian equilibria ${ }^{7}$ of the game where second-stage innovators play pure strategies are as follows:

First-stage innovator both types of innovator invest and set the royalty level as a function of their beliefs about the sampling level, $k$, in the following way:

$$
r(k)= \begin{cases}r_{H} & k>k_{\alpha} \\ r_{L} & k<k_{\alpha} \\ \text { mixed strategy }\left(r_{L}, r_{H}\right) \text { with prob }\left(x_{\alpha}, 1-x_{\alpha}\right) & k=k_{\alpha}\end{cases}
$$

Where: 


$$
x_{\alpha}=1+\frac{T}{p^{\prime}\left(k_{\alpha}\right)\left(v_{H}-v_{L}\right)}
$$

Second-stage innovators: a second-stage innovator will invest if and only if the realized value of her innovation is greater than the royalty rate (note that even with a mixed strategy by the first-stage innovator the second-stage innovator knows the royalty rate with certainty at the point of investment). The sampling level will be chosen as follows:

$k= \begin{cases}k_{2} & k_{2}<k_{\alpha} \\ k_{\alpha} & k_{2} \geq k_{\alpha}\end{cases}$

Proof: We are restricting to the case where second-stage innovators choose pure strategies (allowing mixed strategies yields similar results but complicates the algebra). We will solve for a subgame perfect nash equilibrium by recursing backwards through the game.

1. Second-stage innovator's investment strategies: Just as in the original model second-stage innovator's move with full knowledge of all variables. In this case an innovator of type $X$ invests if and only if net profits from investing, $v_{X}-r-k T$ are greater than $-k T$ the payoff from not investing (sampling costs are sunk). Hence the investment strategies are the same as in the basic model: a second-stage innovator invests if and only if $v_{X} \geq r$.

2. Royalty levels: Using subgame perfection we can focus purely on the post sampling stage of the game. From the point of view of the first stage-innovator the payoffs and model are exactly as in our basic model. Let $G(r)$ be the cumulative distribution function over royalties representing the first-stage innovator's mixed strategy. Then the payoff is given by:

$$
\int_{0}^{v_{L}} r \cdot d G(r)+\int_{v_{L}}^{v_{H}} r \cdot d G(r)+\int_{v_{H}}^{\infty} 0 \cdot d G(r)
$$

Maximizing with respect to $G(r)$ immediately gives that, just as for the basic model, an optimal mixed strategy can only consist of some combination of the pure strategy $r_{L}=v_{L}$ and the pure strategy $r_{H}=v_{H}$. Let us suppose that these two pure strategies are played these with probability $x, 1-x$. Revenue from royalties is then:

$r_{L}(1-x)+(1-p(k)) r_{H} x=r_{L}+x \cdot\left((1-p(k)) r_{H}-r_{L}\right)$

Maximizing revenue requires $x=0$ if the term in brackets is less than zero, $x=1$ if the term in brackets is greater than 0 , and allows any value of $\mathrm{x}$ if the term in brackets is zero. By the definition of $k_{\alpha}$ (see above) these 
conditions correspond to the sampling level being less than, greater than or equal to $k_{\alpha}$. Thus the first-stage innovator's royalty strategy as a function of their belief about the level of sampling is (note precise value of $x$ will defined below):

$r(k)=\left\{\begin{array}{lr}r_{H} & k>k_{\alpha} \\ r_{L} & k<k_{\alpha} \\ \text { mixed strategy }\left(r_{L}, r_{H}\right) \text { with prob }(x, 1-x) & k=k_{\alpha}\end{array}\right.$

3. Sampling level: Recall that second staget innovators are playing pure strategies. Payoffs as a function of the two possible royalty level are as follows:

\begin{tabular}{|c|c|}
\hline $\mathbf{R L}$ & $\mathbf{R H}$ \\
\hline$\Pi(k)=p(k)\left(v-r_{L}-c_{H}-k \mathbf{T}\right)+(1-p(k))\left(v-r_{L}-c_{L}-k \mathbf{T}\right)=-k \mathbf{T}+(1-p(k))\left(v_{H}-v_{L}\right)$ & $-k \mathbf{T}$ \\
\hline
\end{tabular}

\section{Payoff for Second Stage Innovator}

Suppose the first-stage innovator use only a high royalty rate $(\mathrm{RH})$ - and so must believe that $k>k_{\alpha}$. Then it is clear that the second-stage innovator's best response is to set $k=0$ for otherwise she is guaranteed to lose money $(-k T)$.

Suppose then that the first-stage innovator chose only a low royalty level $(\mathrm{RL})-$ and so must believe that $k<k_{\alpha}$. Then the second-stage innovators best response is the sampling level that maximizes profits. The first order condition $\Pi^{\prime}(k)=0^{8}$ giving:

$p^{\prime}(k)=\frac{-\mathbf{T}}{v_{H}-v_{L}}$

The solution of this equation was defined above to be $k_{2}$. (Remark on the first order condition: here both firms engage in production and the effect of sampling will be on the cost type, i.e. it will not effect the royalty paid or whether a firm invests. Hence the sampling level will be chosen so that the marginal gain in terms of lower costs, $p(k)\left(v_{H}-v_{L}\right)$, equals the marginal sampling costs, $\mathrm{T}$.)

Now if $k_{2}>k_{\alpha}$ then this level of sampling is inconsistent with the first-stage innovator's beliefs and so cannot be an equilibrium strategy. In fact because of the consistency of beliefs no equilibrium strategy can involve having $k>k_{\alpha}$. However if $k_{2} \leq k_{\alpha}$ we have a pure strategy equilibrium with the second-stage innovator playing $k_{2}$. 
Suppose now that $k_{2}>k_{\alpha}$. From what we have just shown it is only possible to have an equilibrium in this case if the first-stage innovator plays a mixed strategy where the low royalty is played with probability $x$. This in turn is possible if and only if first-stage innovator believes the second-stage innovator is sampling at level $k_{\alpha}$.

For this to be an equilibrium we require $k_{\alpha}$ to be a best response to the first-stage innovator's mixed strategy, i.e. $k_{\alpha}$ must maximize expected profits. Thus we must show the existence of mixed strategy $(x)$ for first-stage innovators such that $k_{\alpha}$ is optimal for second-stage innovators. Profits in this case are given by:

$x p(k) \cdot-k \boldsymbol{T}+(1-x)(1-p(k))\left(-k \boldsymbol{T}+v_{H}-v_{L}\right)=-k \boldsymbol{T}+(1-x)\left(1-p(k)\left(v_{H}-v_{L}\right)\right.$

The solution, $\mathrm{k}$, is given implicitly by:

$p^{\prime}(k)=\frac{-\mathbf{T}}{(1-x)\left(v_{H}-v_{L}\right)}$

Since $p^{\prime}<0$ we have, denoting $k(x)$ as the solution of this as a function of $x$, that $k^{\prime}(x)<0$. Since $k(0)=k_{2}>k_{\alpha}$ and that as $x \rightarrow 1$ the RHS of the above takes arbitrarily large negative values, by the intermediate value theorem there must exist a unique $x_{\alpha} \in(0,1)$ such that $k\left(x_{\alpha}\right)=k_{\alpha}$.

First-stage innovators investment strategy: finally as with our basic model first-stage innovators of both types invest because with royalty income net profits will be non-negative.

QED.

\section{Welfare}

For the calculation of welfare we proceed as in the original model. A proportion $q$ of first-stage innovations are low value $\left(v_{L}^{0}<0\right)$ and only occur when there is royalty income. Analogously to the basic model define $v^{0}=q v_{L}^{0}+(1-q) v_{H}^{0}$ and $v(k)=-k \mathrm{~T}+(1-p(k)) v_{H}+p(k) v_{L}$ (the value generated by a second-stage innovator sampling at level $k$ ). Further define $v(\alpha)=v\left(k_{\alpha}\right), v(2)=v\left(k_{2}\right)$. Then the level of welfare, both with and without intellectual property, as well as the net difference between the two regimes, can be summarized in the following table: 


\begin{tabular}{|c|c|c|}
\hline & $\boldsymbol{k}_{2}<\boldsymbol{k}_{\alpha}$ & $\boldsymbol{k}_{2} \geq \boldsymbol{k}_{\alpha}$ \\
\hline $\begin{array}{l}\text { Payoff to } \\
\text { First Stage } \\
\text { Firms (IP) }\end{array}$ & $v^{0}+v_{L}$ & $v^{0}+v_{L}$ \\
\hline $\begin{array}{l}\text { Payoff to } \\
\text { Second } \\
\text { Stage Firms } \\
\text { (IP) }\end{array}$ & $-k_{2} \boldsymbol{\top}+\left(1-p\left(k_{2}\right)\right)\left(v_{H}-v_{L}\right)$ & $-k_{\alpha} \boldsymbol{\top}+\left(1-x_{\alpha}\right)\left(1-p\left(k_{\alpha}\right)\right)\left(v_{H}-v_{L}\right)$ \\
\hline Welfare (IP) & $v^{0}+v(2)$ & $v^{0}+\left(v(\boldsymbol{\alpha})-x_{\alpha} p\left(k_{\alpha}\right) v_{L}\right)$ \\
\hline $\begin{array}{c}\text { Welfare } \\
\text { (NIP) }\end{array}$ & $(1-q)\left(v_{H}^{0}+v(2)\right)$ & $(1-q)\left(v_{H}^{0}+v(2)\right)$ \\
\hline $\begin{array}{c}\text { Net } \\
\text { Difference } \\
\text { (IP - NIP) }\end{array}$ & $q\left(\left(v_{L}^{0}+r_{L}\right)+\left(v\left(k_{2}\right)-r_{L}\right)\right)$ & $S$ \\
\hline
\end{tabular}

\section{Total Welfare}

Where $S$ is given by:

$S=q v_{L}^{0}+v(\alpha)-(1-q)\left(v(2)-x_{\alpha} p\left(k_{\alpha}\right) v_{L}\right.$

Proposition 6: When $k_{2}<k_{\alpha}$ it is optimal to have an IP regime.

Proof: analogously to the low royalty case in the basic model in this situation all second-stage innovators invest so there is no hold-up from having intellectual property. At the same time, intellectual property allows some first-stage innovators to engage in production who wouldn't be able to do so otherwise. Formally in this case the welfare difference between the IP and NIP regime is:

$q\left(\left(v_{L}^{0}+r_{L}\right)+\left(v\left(k_{2}\right)-r_{L}\right)\right)$

Both the first term (by the assumption that the royalty is sufficient to allow production) and the second (since second-stage innovators are making non-negative profits) are positive. Hence the sum is positive and welfare is higher with intellectual property.

Proposition 7: If $k_{2} \geq k_{\alpha}$ then it is optimal to have an IP regime as opposed to a no IP (NIP) regime if and only if:

$q \geq q^{m} \equiv \frac{(v(2)-v(\boldsymbol{\alpha}))+x_{\alpha} p\left(k_{\alpha}\right) v_{L}}{(v(2)-v(\boldsymbol{\alpha}))+x_{\alpha} p\left(k_{\alpha}\right) v_{L}+\left(\left(v(\boldsymbol{\alpha})-x_{\alpha} p\left(k_{\alpha}\right) v_{L}\right)-\left(-v_{L}^{0}\right)\right)}$ 
Proof: An IP regime is optimal compared to a no IP (NIP) if and only if $S \geq 0$ (assume that with a tie we choose the IP regime). Some rearranging yields:

$S=q\left(v(2)+v_{L}^{0}\right)-\left(v(2)-v(\mathbf{\alpha})-x_{\alpha} p\left(k_{\alpha}\right) v_{L}\right.$

Thus, for intellectual property rights to be preferable to no intellectual property rights requires:

$q \geq q^{m} \equiv \frac{(v(2)-v(\boldsymbol{\alpha}))+x_{\alpha} p\left(k_{\alpha}\right) v_{L}}{(v(2)-v(\boldsymbol{\alpha}))+x_{\alpha} p\left(k_{\alpha}\right) v_{L}+\left(\left(v(\boldsymbol{\alpha})-x_{\alpha} p\left(k_{\alpha}\right) v_{L}\right)-\left(-v_{L}^{0}\right)\right)}$

Where $q^{m}$ has been defined as the probability of a low value first-stage innovation which leaves one indifferent between having and not having intellectual property rights. QED.

Remark: In words $q^{m}$ can be be written as:

$q^{m} \equiv \frac{\text { Benefit of Higher Sampling w/o IP }+ \text { Hold-up Cost }}{\text { Benefit of Higher Sampling w/o IP }+ \text { Hold-up Cost }+ \text { Net Surplus under Licensing }}$

\section{Policy Implications}

From our calculations of welfare it follows that we should choose to have intellectual property rights if $k_{2} \leq k_{\alpha}$ or if $k_{2}>k_{\alpha}$ and $q \geq q^{m}$.

Now $q^{m}$ increases in $k_{2}$ and decreases in $k_{\alpha}$. Thus the policy choice is directly related to the relative sizes of these different sampling levels.

What can we say about these two values as a function of the underlying parameters? Recall that the probability of a low value innovation goes down with sampling $\left(p^{\prime} \leq 0\right)$ but at a diminishing rate $\left(p^{\prime \prime}>0\right)$ and that:

$$
\begin{aligned}
& p\left(k_{\alpha}\right)=\frac{v_{H}-v_{L}}{v_{H}} \\
& p^{\prime}\left(k_{2}\right)=\frac{-\boldsymbol{T}}{v_{H}-v_{L}}
\end{aligned}
$$

Then:

- Reducing sampling costs, $\mathrm{T}$, increases the level of optimal sampling $k_{2}$ but leaves $k_{\alpha}$ unaffected.

- Increasing the advantage of high value over low value innovations ( $v_{H}-v_{L}$ ) increases the optimal level of sampling, $k_{2}$, but reduces $k_{\alpha}$ the sampling level at which a high royalty is charged. Intuitively: if the differential between high and low value second-stage innovations is 
larger, then the net change in revenue for a first-stage innovator's from switching to a high royalty rate must increase (loss of royalty revenue from low-value second-stage innovations is lower relative to royalty from high-value second-stage innovations). Hence, the proportion of high value second-stage innovations $(1-p(k))$ at which the switch to a high royalty rate is made is smaller.

- Increasing the value of a second-stage innovation, $v$, while leaving all other parameters constant increases $k_{\alpha}$ but leaves the optimal level of sampling unchanged (the intuition is exactly the same as for the previous item).

These results suggest the following, corresponding, conclusions for policy:

1. Reducing sampling costs make it more likely that a freer (no intellectual property rights) regime will be optimal. This is because the 'optimal' level of sampling $\left(k_{2}\right)$ will be sufficiently greater than the restricted level of sampling $\left(k_{\alpha}\right)$. This in turn means that having intellectual property rights results in a combined loss from hold-up of second stage products $\left(x_{\alpha} \cdot p\left(k_{\alpha}\right)\right)$ and lower average value of second-stage innovations which outweighs the benefits of more first stage (and dependent second-stage) innovations (when compared with not having intellectual property rights).

2. Increasing the differential between high and low value second-stage innovations (which could be interpreted as sampling becoming more important for product quality) makes it more likely that a freer (no intellectual property rights) regime will be optimal. Conversely increasing the value of an innovation while leaving value differentials constant (which also corresponds to value differentials being less important) makes it more likely that an intellectual property rights regime will be optimal. 


\section{Conclusion}

In this paper we have examined how asymmetric information about the value of follow-on innovations, combined with intellectual property rights such as patents, can result in hold-up. Presenting the policy decision as a choice between having or not having intellectual property rights, we have shown that, in contrast to parts of the previous literature, in some circumstances it may be optimal not to have intellectual property rights. For whilst intellectual property rights help transfer income from second-stage to first-stage innovators they can also lead to hold-up with a resulting reduction in second-stage innovation.

In the first, and simpler, model presented, our results were summarized in a plot showing optimal policy as a function of the fundamental variables (the probabilities of high or low value innovations occurring at the two different innovation stages). The introduction of intellectual property rights in this model has two basic effects. On the one hand, there are the benefits of increased first-stage innovation as revenue is transferred to first-stage innovators. On the other hand, there are costs in terms of fewer second-stage innovations due to hold-up. In some circumstances the benefits will exceed the costs and we should have (stronger) intellectual property rights. In other cases they will not and we should have weaker (or no) intellectual property rights. In particular, we have shown that, if the probability of a low value second-stage innovation was high enough (but not too high), compared to the probability of a low value first-stage innovation, then a regime without intellectual property rights would be preferable.

Next, we extended this basic model by introducing 'sampling'. Focusing on the case of royalty-after-sampling we demonstrated the existence of an equilibrium. The major result here was that the presence of intellectual property rights may restrict the level of sampling below what would be socially optimal. Therefore, in addition to the basic trade-off mentioned above between more first-stage innovations and fewer second-stage ones, there is the additional factor that those second-stage innovations, which occur under an intellectual property rights regime, have lower average value due to a lower level of sampling. Examining this trade-off, we find that the lower the cost of sampling and the greater the differential between the low and high values of second-stage innovations, the more likely it is that a regime without intellectual property rights will be preferable.

Thus, technological change which reduces the cost of encountering and trialling new 'ideas' should imply a reduction in the socially optimal level of intellectual property rights such as patents and copyright. A perfect case of such technological change in recent years can be found in the rapid advances in computers and communications. These advances have, for 
example, dramatically reduced the cost of accessing and re-using cultural material, such as music and film, as well as greatly increasing the number of 'ideas' that a software developer can encounter and trial.

Finally, we should emphasize that there remains plentiful scope to improve and extend the present paper. For instance, it was assumed that non-licensing income $(v)$ for the first-stage innovator was unaffected by the intellectual property rights regime. However this is unlikely to be the case and the model could be improved by the inclusion of the direct effect of no intellectual property rights on the revenue of the first-stage (and second-stage) innovator ${ }^{9}$.

It would also be useful to extend the analysis to the case of a continuous distribution of innovation values, as well as to investigate the consequences of making sampling costs a function of the intellectual property rights regime. It would also be valuable to examine what occurs when the structure of innovation is more complex, for example by having second-stage inventions incorporate many first-stage innovations (a componentized model) or having heterogeneity across innovations with some developments used more than others. Finally, one of the most important extensions would be to properly integrate transaction costs into the analysis. Transaction costs relating to both the acquisition of information and the execution of contracts are significant and without them we lack a key element for the furtherance of our understanding of the process of innovation both in this model and in general. 


\section{Endnotes}

1. A monopoly right (intellectual property right) such as a patent or a copyright confers the right to exclude not simply direct copies but also products that are sufficiently similar. The term lagging/leading breath are often used to denote the space of inferior/superior (respectively) products that are excluded by the patent/copyright (i.e. taken as infringing the monopoly).

2. See e.g. Eisenberg (1998), Hall (2001), Cockburn (2005).

3. Of course, for consistency, the collective distribution of the values/costs of all second-stage innovators should correspond to the prior of the first innovator.

4. Given that we are dealing with cumulative innovation some readers might prefer the infringing (I) vs. non-infringing ( $\mathrm{NI}$ ) dichotomy with its implication of a distinction between 'horizontal' imitation and 'vertical' improvement of a product. However there are two reasons to prefer having a simple choice of intellectual property rights vs. no intellectual property rights. First in practice the difference between 'vertical' and 'horizontal' changes to products is not always obvious and the monopoly afforded by the IP right operates equally against the makers of both types of changes. Second, and relatedly from a policy makers point of view, breadth and/or height are not easily legislated (and are usually under the control of an external administrative body such as the patent office) while the choice between granting and not granting monopoly protection is clear. Witness, for example, the recent debate over 'software' patents in Europe, or the continuing difficulties in altering patent office (or judicial) norms experienced in the US once the patentability of software and business methods was accepted. $\downarrow$

5. See e.g. Malcolm Gladwell, The New Yorker, 2004-11-22, Something Borrowed: Should a charge of plagiarism ruin your life?, also http://www.low-life.fsnet.co.uk/copyright/part3.htm\#copyrightinfringement for information about sampling in dance and hip-hop music. $\downarrow$

6. The author has also examined the royalty-before-sampling but the situation is considerably more complex and yields fewer insights for policy. In the interests of brevity it has therefore been omitted. The interested reader who wishes to have the details is invited to contact the author. $\downarrow$

7. We should distinguish between two possibilities regarding knowledge of the sampling level available to first-stage innovators. In the first case the first-stage innovator does observe the sampling level. In the second case the first-stage innovator does not know the sampling level. In what follows we focus on the case where the sampling level is unobserved though the results are little changed when it is 
observed.

8. The second order condition, $\Pi " \leq 0$, is easily checked:

$\Pi^{\prime \prime}=-p^{\prime \prime}(k)\left(v_{H}-v_{L}\right) \leq 0$ since, by assumption, $p^{\prime \prime}(k) \geq 0$.

9. The paper of Bessen and Maskin (2006) would have some relevance here. 


\section{Bibliography}

Anand, B. and Khanna, T. 2000. The Structure of Licensing Contracts, The Journal of Industrial Economics, 48:1, pp. 103-135.

Bessen, J. 2004. Hold-up and Patent Licensing of Cumulative Innovations with Private Information, Economics Letters pp. 321-326.

Bessen, J. and Maskin, E. 2006 (1999). Sequential Innovation, Patents and Imitation. (mimeo)

Chang, H. 1995. Patent Scope, Antitrust Policy, and Cumulative Innovation, Rand Journal of Economics, 26:1, pp. 34-57.

Cockburn, I. 2005. Blurred Boundaries: Tensions Between Open Scientific Resources and Commercial Exploitation of Knowledge in Biomedical Research (mimeo).

Denicolo, V. 2000. Two-Stage Patent Races and Patent Policy, Rand Journal of Economics, 31:3, pp. 488-501.

Eisenberg, R. and Heller, M. 1998. Can Patents Deter Innovation? The Anticommons in Biomedical Research, Science pp. 690-701, 1998-05-01.

Gallini, N. 1992. Patent Policy and Costly Imitation, Rand Journal of Economics, 22:1, pp. 52-63.

Green, J. and Scotchmer, S. 1995. On the Division of Profit between Sequential Innovators, Rand Journal of Economics, 26:1, pp. 20-33.

Hall, B. and Ziedonis, R. 2001. The patent paradox revisited: an empirical study of patenting in the U.S. semiconductor industry, 1979-1995, Rand Journal of Economics, 32:1, pp. 101-128.

Matutues, C.; Regibeau, Pierre. and Rockett, C. 1996. Optimal Patent Design and the Diffusion of Innovations, Rand Journal of Economics, 26:1, pp. 60-83.

Menell, P. and Scotchmer, S. 2005. Intellectual Property (mimeo). http://socrates.berkeley.edu/ scotch/ms_06_10_2005.pdf

O'Donoghue, T.; Scotchmer, S. and Thisse, J. 1998. Patent Breadth, Patent Life, and the Pace of Technological Improvement, Journal of Economics and Management Strategy pp. 1-32. 